DOI: $10.1515 /$ ausfm-2015-0018

\title{
Visual Composition of Bodily Presence. A Phenomenological Approach to Paul Thomas Anderson's The Master
}

\author{
Zsolt Gyenge \\ Moholy-Nagy University of Art and Design Budapest (Hungary) \\ E-mail: zsengezsolt@yahoo.com
}

\begin{abstract}
The description and interpretation of the visual composition of a film is crucial in understanding the effects of moving images and their specific role in the contemporary context of intermediality. The phenomenological approach, based on the precise depiction of the lived perceptual experience and its integration in the process of interpretation, offers a powerful tool for critical analysis. Although this theoretical framework opens up many different approaches, in this paper I will focus on Merleau-Ponty's phenomenological account of perception and on the viewer experience described by Vivian Sobchack with the self-contradictory term "a film's body." After studying this concept and its role in film analysis, as used by Sobchack, based on the term double-sided and fissured experience the paper offers an alternative approach which, compared to the earlier ones, seems to be more fruitful in understanding the act of vision and the embodied viewer experience constructed by a moving picture. The last part of the paper demonstrates, through the example of Paul Thomas Anderson's The Master (2012), how crucial the embodied viewer experience can be in the understanding of moving images. The analysis of the visual system of this film will show how the main problem of the whole story is re-created, re-presented in the visually triggered bodily experience of the viewer.
\end{abstract}

Keywords: phenomenology, perception, film’s body, Paul Thomas Anderson, The Master.

"The first capital event in the history of filmic representation was unquestionably the recognition of the narrative potential of the image, by way of its assimilation to a gaze" - argues Jacques Aumont, making it clear that it would be impossible to disregard the problem of the gaze in any description and analysis of the cinematic experience $(1989,2)$. One cannot emphasize enough how crucial it is that, opposed to still images, in cinema, all that appears on screen is considered as being seen from somewhere or by someone, and it is always linked to a "source" 
by the viewer. This is the reason many film theorists have analysed the visual, narrative, and symbolic function of the cinematic gaze. What phenomenology can add to the analysis is a focus on a specific aspect of this problem, namely that it is an embodied gaze. If we are to consider the cinematic image as being linked to a certain bodily presence, we have to understand its consequences for the process of meaning generation, where we will have to deal with the description and understanding of non-visual experiences. Before moving on to the analysis of Paul Thomas Anderson's film, I will give a brief overview of the most important approaches in film phenomenology and point out the aspects which can help create a useful framework for the analysis of moving pictures.

All phenomenological approaches and analyses are linked to perception, they are often dealt together within film theory with cognitive sciences or ecological analyses. ${ }^{1}$ However, there is an important difference between these theories. It is true that phenomenology is linked to perception, but its main goal is not to understand perception in itself, but to understand the world through perception; while cognitive sciences are mostly trying to understand how we perceive and understand the world that surrounds us. As Jennifer M. Barker puts it: "Phenomenological description seeks to identify the underlying structures of the phenomenon at hand by studying its intimate entailment with the intentional act of perception to which the phenomenon is present" $(2009,11)$.

Although he has written almost nothing on cinema itself ${ }^{2}$, nearly all phenomenological film theories are based on Maurice Merleau-Ponty's groundbreaking work, his most often cited lecture, The Film and the New Psychology (1966). An impressive part of his phenomenology is grounded on the critique of the Cartesian view of the world. Merleau-Ponty's phenomenological theory of perception is based on the belief that the division between mind and body is a false one, and thus perception and understanding, bodily apprehension and comprehension are part of one and the same process, they happen simultaneously. As he expresses in L'Oeuil et l'esprit (Merleau-Ponty 1964b), body is nothing else but the entailment of vision and movement, because the moving human body is part of the visible world. This means that my perception,

1 Phenomenology is often considered as one of the so-called reception or interpretation theories, and thus it is often dealt together with cognitive theories. For example, when trying to find similarities between different types of (film) theoretical discourses within the Humanities, Henry Bacon argues that the combination of Merleau-Ponty's phenomenology and the hermeneutics of Ricoeur "can furnish us with conceptual tools for appropriating the discoveries and insights of cognitivism, ecological film theory, neoformalism, historical poetics” (Bacon, 2005).

2 Focusing openly on cinema we only find his brief lecture entitled The Film and the New Psychology (1966). 
my visual recording system is not outside the world it sees but constitutes an organic part of it. And thus, according to Merleau-Ponty, seeing is not an act of thinking, because "immersed in the visible by his body, itself visible, the see-er does not appropriate what he sees; he merely approaches it by looking, he opens onto the world" (Merleau-Ponty 1993, 124).

At the heart of Merleau-Ponty's theory on perception is the idea that "my body simultaneously sees and is seen," so my body is in every sense part of the world, of the things it observes. And thus, the act of seeing originates from the world, the medium of things. This is what phenomenology calls chiasm, or chiastic structure: the one who perceives is in the very same moment perceivable, exposed to the perception of the world he observes. Merleau-Ponty's concept of chiasm describes a perception which implies a strong connection between seeing and that which is seen. In this respect, seeing is similar to touching, where there is a relation between the act of touching, the movement of one's hand, and the touched surface. The description of the left hand touching the right hand, the experience of touching and being touched, of being simultaneously the subject and the object of experience is central to his theory of perception. Chiasm is about the interconnected nature of the seeing subject and the seen object. And this results in a primordial subjectivity: we simply cannot transcend our embodied, material, and irreducible relation with the world (cf. Merleau-Ponty 2002 and Merleau-Ponty 1964a).

Transposing Merleau-Ponty's phenomenology into the realm of moving pictures, Vivian Sobchack argues that the main novelty in cinema is that it able to reproduce this everyday experience: we are seeing and being seen at the same time. As she explains it, "the moving picture not only visibly represents moving objects but also - and simultaneously - presents the very movement of vision itself" (Sobchack 2004a, 146). Hence, for the first time in the history of visual representation, cinema has provided "objective insight into the subjective structure of vision and thus into oneself and others as always both viewing subjects and visible objects" (my emphasis, Sobchack 2004a, 149). So, in Sobchack's view, film expresses perception. "To exist in a lived-body is always to do both, and so the film is, essentially, perception and expression in motion” (Barker 2009, 8). This also means that both film and viewer might engage in the act of looking. We should therefore acknowledge that filmmakers not only construct images and visual compositions, but at the same time they also construct a specific act of seeing, an act of vision, an act of perception through the moving image. It will be demonstrated further on, through the analysis of The Master, that the main 
ingredient of Paul Thomas Anderson's directing is the creation of a very specific way of perception, of an embodied act of seeing.

The term embodied act of seeing makes it necessary to take into consideration other senses than vision - which is, in fact, one of the main concerns of film phenomenology (cf. Barker 2009, Marks 2000, Sobchack 2004). If film is considered an audiovisual medium, how is it possible that it is capable to trigger, or evoke (the difference between the two is a matter of discussion in itself) other sensations, such as touch, smell or taste? One side of the problem is connected to the acceptance or denial of the primacy of vision. Are haptic sensations really taking place (as Sobchack suggests, 2004c), or do we just imagine them due to our visual experience? This is an important question because if we want to analyse films through perception, we must be able to say that perceptual experience is really taking place. Not being entitled to make final judgements on the issue, I would go with Merleau-Ponty, who stated that even what is behind our back, even "the gramophone playing in the next room [...] still counts in my visual field" (Merleau-Ponty 2002, 323). Another side of the issue is related to the actual place of this embodiment: does it take place "here," or rather "there" (in the diegetic world of the movie)? Before elaborating further on these questions, several terms and discussions of film phenomenology have to be considered.

When moving to a phenomenological approach of the cinematic experience, as Jennifer M. Barker puts it, the analyst "focuses neither solely on the formal or narrative features of the film itself, nor solely on the spectator's psychic identification with the characters or cognitive interpretation of the film. Instead, phenomenological film analysis approaches the film and the viewer as acting together, correlationally, along an axis that would itself constitute the object of study" (Barker 2009, 18).

It is at this point that the relationship between viewer and film, between our and the film's body comes in. In her now famous book entitled The Address of the Eye (Sobchack 1992), Vivian Sobchack created the notion of the film's body, which is used to describe the embodied nature of the cinematic experience. We can talk about the film's body because - as argued before - we can see the film "seeing:" "we see its own process of perception and expression unfolding in space and time" (Barker 2009, 9). The main issue here is related to the problem of the gaze: film is always the re-presentation of the act of seeing an Other. So, the viewer not only sees a world shown by the film, but he/she observes a world seen by someone - this is why film is conceived of as a seeing subject. Sobchack considers that the source of the cinematic gaze is not a transcendental eye, but rather an enworlded act of seeing 
that is capable of understanding materiality. "A phenomenological description of the act of viewing inevitably leads to an embodied viewer - not visible in the act or its productions but generative of the act and its existentially directed and diacritical structure" (Sobchack 1992, 135, my emphasis). If there is an invisible, embodied observer who generates the act of seeing itself, then - according to Sobchack we have to speak of the film's body. Therefore, Sobchack argues that film is more than pure vision; its existence implies a certain kind of body. "Realized by the physical presence of the camera at the scene of the cinematography yet not the same as the camera, the film's 'body' needs not be visible in its vision - just as we are not visible in our vision as it accomplishes its visual grasp of things other than itself" (Sobchack 1992, 133). The perceptual engagement with the film experience is enabled by an eye that does not belong solely to the filmmaker, to the camera, or to the spectator, so "the film exists as the visible visual relation between an embodied eye and a sensible world" (Sobchack 1992, 203). It is neither the camera nor the projector, neither the filmmaker nor the spectator who mediates between the perceiving act and the intentional object - this relation, this mediating entity is described by Sobchack with the term the film's body. Although it seems to be clear that while watching a film we experience from inside an act of seeing, it is important to note that this still does not appear to us as our own vision. "Even as I perceive it as lived from within vision, it does not emerge as my own lived vision because I am seeing it as visible from without” (Sobchack 1992, 138-139).

There are many debates within film theory about the true origin of vision in cinema. Is it the film's vision? Or does it belong to the viewer? Yet again, is it the author's? While he cannot be considered a phenomenologist, in his essay Moving Pictures, Arthus Danto grasps this problem from the perspective of camera movement: "I think, in a way, the kinetification of the camera goes some way toward explaining the internal impact films make upon us, for it seems to overcome, at least in principle, the distance between spectator and scene, trusting us like movable ghosts into scenes which a-kinetic photography locates us outside of, like disembodied cartesian spectators" (Danto 1979, 19). In his view it is us, the viewers, who are thrown in the world of the film, but our presence is only a ghostly one. This is a very important idea because it very precisely shows this uncertain, double-sided and fissured presence of us, viewers in the film experience. Film is neither the viewer's gaze (because we do not have the visual and motoric freedom that we would enjoy if we really were in the space shown by the camera); nor is it the author's gaze, because he/she has chosen this image from a much larger "reality." 
Analysing Kiarostami's cinema, Jean-Luc Nancy argues that it is the director's gaze that appears on screen, ${ }^{3}$ and it is important to observe the way he describes the viewer's relation to the moving image: "It is not about passivity, even less about captivity; it is about adapting, according [s'accorder] ourself to a gaze, in order to watch when it comes to us. Our gaze is not captive, and if captivated, it is because it is requested, mobilized" (Nancy 2001, 17, translation mine).

All these descriptions refer to a fissured and double-sided experience in which both identification and otherness have their place. Contrary to Sobchack, I don't think that a concept such as the film's body is needed to render the experience understandable, and it especially does not help the understanding, analysis and interpretation of actual films - which is the goal of my phenomenological approach. If we talk of the film's body, we will soon face the problem of the lack of visibility of this body. As we are not able to see the film's body from one shot to another, the visibility of the seeing subject, which - even according to Sobchack - is the most important element of the cinematic experience, is missing from this approach. Within the film, one is capable of experiencing the visibility of the seeing bodies, yet this is true not for the immaterial body of the film, but rather for the characters visible on screen (since identification takes place mostly with them), and for us, viewers. So, when I experience the visibility of the seeing subject as being mine, it is often the visibility of the vision of a character within the film, not the visibility of the film itself. The main problem is that weird experience of being in the film and outside it at the same time: "Watching a film, we are certainly not in the film, but we are not entirely outside it, either. We exist and move and feel in that space of contact where our surfaces mingle and our musculatures entangle. [...] This sense of fleshy, muscular, visceral contact seriously undermines the rigidity of the opposition between viewer and film" (Barker 2009, 12-13). Although it is clear that, for Merleau-Ponty, all perception is embodied perception, it seems to me that the concept of the film's body is an unnecessary theoretical construction that serves best those who try to undermine the credibility of phenomenology by pointing out its (supposedly) fuzzy, unclear, poetic notions. In my view, what we are dealing with here is an experience of fissured double-sidedness. In other words, although a process of perception clearly goes on, an act of seeing and hearing takes place in the film and is perceived by the viewer, we do not necessarily need to posit a body to film. If - as true phenomenologists - we try to understand the thing, the film itself,

3 In my view, in Kiarostami's cinema it is essential that we are not dealing with a modernist selfreflexive attitude which emphasizes its own constructed nature. Rather, I would argue that he anchors every gaze in the represented reality, thus making us aware of the constructed nature of reality itself. 
and not the process of perception, if we are aiming for a phenomenological theory of film analysis, then there is no need for the complicated concept of the film's body.

Let me examine this problem from another angle. Merleau-Ponty's phenomenology not only posits that the division of mind and body is a false one as I presented earlier -, but also questions the boundary between body and world, between the subject and object of perception. The reversibility or chiastic nature of perception is central to his theory, as he argues that the common materiality shared by us and the world, the common materiality of our own body and the flesh of the world is which makes perception possible in the first place. If we relate this idea to cinema, we can say that the whole issue of the film's body, of this invisible yet bodily presence of the viewer in the world of the film, is related to the problem of subject and object, to the relationship of the viewer's own body and the external world. Vivian Sobchack uses the emotions of passion and suffering to elaborate on this idea (Sobchack 2004b). She writes that, on the one hand, suffering "enhances the awareness of oneself as a subjective object: a material being that is nonetheless capable of feeling what it is to be treated only as an object" (Sobchack 2004b, 288). When tortured or being forced to suffer a non-intentional wordly phenomenon, in fact, we suffer a diminution of our subjectivity, thus we experience what it is like to be a material object. We can find an extraordinary example of this in The Master, in the scene where Freddie is "forced" to walk up and down in a room, hitting the wall with his almost objectified body - in order to be capable of reaching a higher understanding of Lancaster's ideas. On the other hand, the passion of devotion, and especially sexual passion, is a devotion to the carnal possession of another, a self-displacement in the flesh of the world. Based on this, Sobchack argues that "it is this sense of passion that provides the material foundations of our aesthetic behaviour toward the world and others" (Sobchack 2004b, 290). And finally she concludes: "I would suggest that it is only through the intimate [...] subjective recognition of ourselves as material objects that we can share in the full being of the world, and [...] feel not merely a superficial passion for the material (that is always other than ourselves) but feel also the existential passion of the material (that is always also ourselves)" (Sobchack 2004b, 296).

The notion of the film's body in fact theorizes this double-sided and fissured experience that we have while watching a film, when we are both outside and inside it at the same time. Really remarkable filmmakers are able to make the construction of the "presence-absence," of this invisible bodily experience a central problem of their art, and are also capable of grounding the main topic of their film in that specific viewer experience which they themselves have created. 
This is the way in which a phenomenological approach can be channelled in a critically productive manner into the analysis of moving pictures.

At this point, I would like to return to the problem of the place of embodiment. If we accept Merleau-Ponty's assumption on the dissolution of the boundary between the subject and object of perception, then we have to say that the whole problem is irrelevant, as the subject and the object of perception are both part of the same world (be that partially the diegetic world of a film). Identification with a character - another issue often brought up in these discussions - is only psychological, not perceptual: the perceptual experience always belongs to the viewer. This justifies the idea of a fissured experience, and this is why, in the example of The Master, a non-visual bodily sensation can occur independently of any of the characters of the movie (as it will be presented later).

When I use phenomenology in my approach to film studies, contrary to most scholars, I do not intend to create a comprehensive phenomenological theory of the filmic representation. Due to my teaching practice and my activity as a film critic I am much more interested in finding approaches that actually help to understand films based on the cinematic experience they create. A phenomenological theory of film analysis could help us understand films not only through their symbolic value, narrative strategy, genre references, or visual style, but through the embodied viewer experience that they enable by the fact that they are viewed as an expression of perception. When scholars speak of a phenomenological approach to cinema, the main idea is that they do not consider the film as text, image, or discourse, but rather they deal with the cinematic experience. This is why, I try to develop a methodology that can be successfully used in the critical approach of moving pictures.

One way to do this would be to follow the scholars whose phenomenological analysis is concerned with the immense possibilities offered by the sensual approach to perception, a phenomenological understanding of the filmic reception that is not limited anymore within the boundaries of visuality. In her book The Tactile Eye, Jennifer M. Barker stresses that “exploring cinema's tactility thus opens up the possibility of cinema as an intimate experience and of our relationship with cinema as a close connection, rather than as a distant experience of observation, which the notion of cinema as a purely visual medium presumes" (Barker 2009, 2). She also points out that by tactility she does not only understand physical contact, but "a profound manner of being." So, Barker extends the notion of tactility beyond touch, to the experience of a bodily being-in-the-world. If we are to accept Merleau-Ponty's description of the chiastic structure of human 
experience, which is actually based on tactility, we can say that touch has a special significance in perception and in our bodily presence. But what is maybe even more important here is that Barker moves the notion of body from the side of the cinematic apparatus, where it has been placed by Sobchack, and deals with it within the context of viewer experience. Beside Barker's book, we should also refer here to several essays written by Sobchack (especially the paper entitled What My Fingers Knew: The Cinesthetic Subject, or Vision in the Flesh, 2004c) and Laura U. Marks's book, The Skin of the Film (2000). Both works emphasize the significance of the non-visual and non-narrative side of the cinematic experience and try to interpret the artworks through the description of non-visual perception.

Although this approach might lead to very sensitive and almost poetic interpretations, this is not the path I would follow. I consider that it is much more productive to focus on the embodied viewer experience that actually takes place during the screening of a moving picture. The reason I have chosen Paul Thomas Anderson's The Master (2012) is that it seems to me that through the composition of the shots and camera movements this film consciously creates an act of vision closely related to the subject of the film.

Kent Jones notes in Film Comment: "Anderson is too interested in Hubbard and Scientology to be content with merely condemning them" (Jones 2012) - this is one of the reasons why we should pay further attention to what this film is about. The phenomenological insight into the film will be based on four scenes or shots that are most enlightening regarding the viewer experience constructed by the filmmaker. I start my analysis of the film with a recurring shot of symbolic significance, which appears in important moments, and not accidentally it is also the very first shot [Fig. 1]. Here we can observe, for about 15-20 seconds, the blue sea that covers the whole screen, from the deck of a ship, whose unseen presence is acknowledged by the fact that the propeller whirls the waves beneath us. It is important that we are not facing forward, in the direction of the movement of the ship, but rearwards, in the direction where it came from. This shot is significant not (only) for its symbolic value, but due to the uncanny bodily experience it creates in its viewer, an experience that is continuously reinforced by the visual composition of the entire film. The uncanny bodily sensation we get here is that of a person going backwards, without being able to watch his/her steps, without being able to see where he/she is heading. It is extremely important to note that this view belongs to none of the characters, so it cannot be considered a POV shot. Although it can be anchored to a certain moment of the plot, as it could have been taken during Freddie's boat trip on Lancaster's yacht, there is no specific 
scene from where this shot could actually originate. This is why I consider this shot as a key sequence destined to reinforce and, to a certain point, unveil the representational strategy of the film.

The second moment I have chosen is a magnificent steadicam shot that could have been included in Kevin B. Lee's remarkable video essay made for Sight\&Sound (Lee 2012a) as probably the most mature example of Anderson's use of this device [Fig. 2]. In my view, it could also be a fine example of how Anderson has moved away from the spectacular use of these kinds of shots, seen in his earlier films, to a more condensed application - a tendency spotted by Lee already in There Will Be Blood (2007). The shot I am referring to starts around 10 minutes into the film and shows the moment when Freddie, working as photographer in a department store, observes his woman colleague wandering around and selling a coat - or, to be more precise, she observes him. The most striking feature of this beautifully choreographed and paced shot is the subtle and changing relationship between the movement of the camera and the movement of the protagonist, the amazing woman. In the beginning, one might think that the shot is taken from Freddie's point of view, but after a few seconds it becomes clear that the camera moves around with great mobility, while he (most probably) remains still in his small photo studio. The focal point of the shot is, in fact, the woman's gaze, who, while moving around the customers, glances back time and again at Freddie. What makes all this uncanny is that we never get to see what she is looking at, and as the minutes pass by, we feel more and more uncomfortable by this. The moment when, towards the end of the shot, she walks toward the receding camera - besides being symbolic - is full of visual and emotional tension, as we just do not get the possibility to see what she is looking at, and what the reaction of Freddie is. It is important to note that the tension does not originate from the identification with the main character (Freddie) but from the fact that the film does not offer us the possibility to turn around - what our natural reaction would be in such situations. It is exactly this almost physical constraint that creates a visually triggered bodily presence for the viewer, who is obliged to consciously acknowledge his or her embodied position within the viewing experience.

The next moment I would like to refer to is a short, 15-second shot, a receding steadicam progress that shows the two main characters, Lancaster and Freddie, leaving the rocks in the desert from where they have dug out the famous box [Fig. 3]. The shot is important for my argument mainly because it proves once again that the visual strategy of not showing the direction where the characters are looking or heading is central in the entire film. This is also probably the moment 
when we start to realize that there are no eyeline match cuts in The Master - no matter how intensely a character is focusing in a certain direction, we will never get a shot showing us what he or she was looking at.

This visual decision becomes evident in the 4-minute-long scene towards the end of the film (it occurs around 1 hour and 50 minutes into the film), when Lancaster tries to make his followers live a certain kind of experience when riding very fast with the motorbike towards a chosen orientation point in the desert [Fig. 4]. This scene is crucial from the point of view of the visual composition of the film because here we can see how step by step this above described strategy changes. It is exactly in the moment when Lancaster realizes that Freddie might not come back that we get to see the first eyeline match cut of the film: finally we are able to look in the direction where the Master is looking. And, not accidentally, this is the moment when Freddie is finally capable of freeing himself from Lancaster's influence.

This embodied viewer experience created by Anderson is important for two reasons. First, we are dealing here with a perceptual experience that is clearly not linked to any kind of identification with a character; this is about our spectatorial presence in the diegetic world of the film. This is also the reason why I have called it a fissured double-sided experience. The second reason is that in The Master we face a synaesthetic perceptual phenomenon, as characterized by Merleau-Ponty, who says that "synaesthetic perception is the rule," and thus it is perfectly possible that we have haptic sensations through sight. "The senses intercommunicate by opening on to the structure of the thing. [...] The form of objects is not their geometrical shape: it stands in a certain relation to their specific nature, and appeals to all our other senses as well as sight" (MerleauPonty 2002, 266-267). This is why we actually perceive, and not only "imagine," this uncanny bodily feeling of the blind spot behind our back.

Finally, in my view, Anderson's coherent visual strategy followed throughout the film is of extremely great importance not simply because it creates a very specific, embodied viewer experience, but also because it is strongly related to the whole topic of the film. Lancaster Dodd's manipulation is, in fact, based on the pattern of nostalgia, on the strategy that he turns his audience's attention towards their past: he talks of their childhood, of their past lives, or of things that happened billions and trillions of years ago. So, while they are looking backwards, he is able to take them where he wants. Now, this manipulation suffered by the characters of the film is translated and then conveyed to us through the construction of a specific act of vision. Due to the composition of the 
shots and the omission of eyeline match cuts, we are able to experience through our bodily presence, in an embodied way, a similar experience to that endured by Freddie and other followers of Lancaster. The immense value of this solution is that it makes us bodily, physically "understand" the intellectual and emotional experience of the main character.

This brief analysis was important to me not only as a possible interpretation of the film, but also because I hope that it proves that a heightened attention to the visually triggered, embodied act of vision, which is, in fact, created in a different way by every moving picture, can actually aid the interpretation and analysis of films. A phenomenologically grounded focus on our viewer experience can become a useful critical tool.

\section{References}

Aumont, Jacques. 1989. The Point of View. Quarterly Review of Film Studies vol. 11 no. 2: 1-22.

Bacon, Henry. 2005. Synthesizing Approaches in Film Theory. The Journal of Moving Image Studies vol. 4: 4-12.

Barker, Jennifer M. 2009. The Tactile Eye. Touch and the Cinematic Experience. Berkeley: University of California Press.

Gorbman, Claudia. 2014. The Master's Voice. Film Quarterly vol. 68 no. 2. http:// www.filmquarterly.org/2015/01/the-masters-voice/. Last accessed 12. 03. 2015.

Danto, Arthur. 1979. Moving Pictures. Quarterly Review of Film Studies vol. 4 no. 1: 4-21.

Jones, Kent. 2012. Paul Thomas Anderson's The Master. Film Comment September/October. http://www.filmcomment.com/article/the-master-paulthomas-anderson-review. Last accessed 04. 03. 2015.

Lee, Kevin B. 2012a. Video: Steadicam Progress - the Career of Paul Thomas Anderson in Five Shots. Sight\&Sound http://www.bfi.org.uk/news-opinion/ sight-sound-magazine/features/video-steadicam-progress-career-paulthomas-anderson-five. Last accessed 13. 03. 2015.

Lee, Kevin B. 2012b. Paul Thomas Anderson - Every Symmetrical Two-Shot. https://vimeo.com/53023544. Last accessed 16. 03. 2015.

Lee, Kevin B. 2013. Paul Thomas Anderson - Every Whip Pan. https://vimeo. com/52970914. Last accessed 16. 03. 2015.

Marks, Laura U. 2000. The Skin of the Film. Intercultural Cinema, Embodiment, and the Senses. Durham: Duke University Press. 
Merleau-Ponty, Maurice. 1993. Eye and Mind. In The Merleau-Ponty Aesthetics Reader: Philosophy and Painting, eds. Galen A. Johnson, Michael B. Smith, 121-150. Evanston, Illinois: Northwestern University Press.

Merleau-Ponty, Maurice. 2002 [1945]. Phenomenology of Perception. London: Routledge Classics.

Merleau-Ponty, Maurice. 1966. Sens et non-sens. Paris: Éditions Nagel.

Merleau-Ponty, Maurice. 1964a. Le visible et l'invisible. Paris: Éditions Gallimard.

Merleau-Ponty, Maurice. 1964b. L'Oeil et l'esprit. Paris: Éditions Gallimard.

Nancy, Jean-Luc. 2001. L'évidence du film. Abbas Kiarostami. Bruxelles: Yves Gevaert Éditeur.

Sobchack, Vivian. 1992. The Address of the Eye. Princeton: Princeton University Press.

Sobchack, Vivian. 2004a. The Scene of the Screen. In Carnal Thoughts. Embodiment and Moving Image Culture, 135-162. Berkeley: University of California Press.

Sobchack, Vivian. 2004b. The Passion of the Material. Toward a Phenomenology of Interobjectivity. In Carnal Thoughts. Embodiment and Moving Image Culture, 286-318. Berkeley: University of California Press.

Sobchack, Vivian. 2004c. What My Fingers Knew: The Cinesthetic Subject, or Vision in the Flesh. In Carnal Thoughts. Embodiment and Moving Image Culture, 53-84. Berkeley: University of California Press. 


\section{List of Figures}

Figure 1. The Master (2012): the image of the sea from the back of a ship.

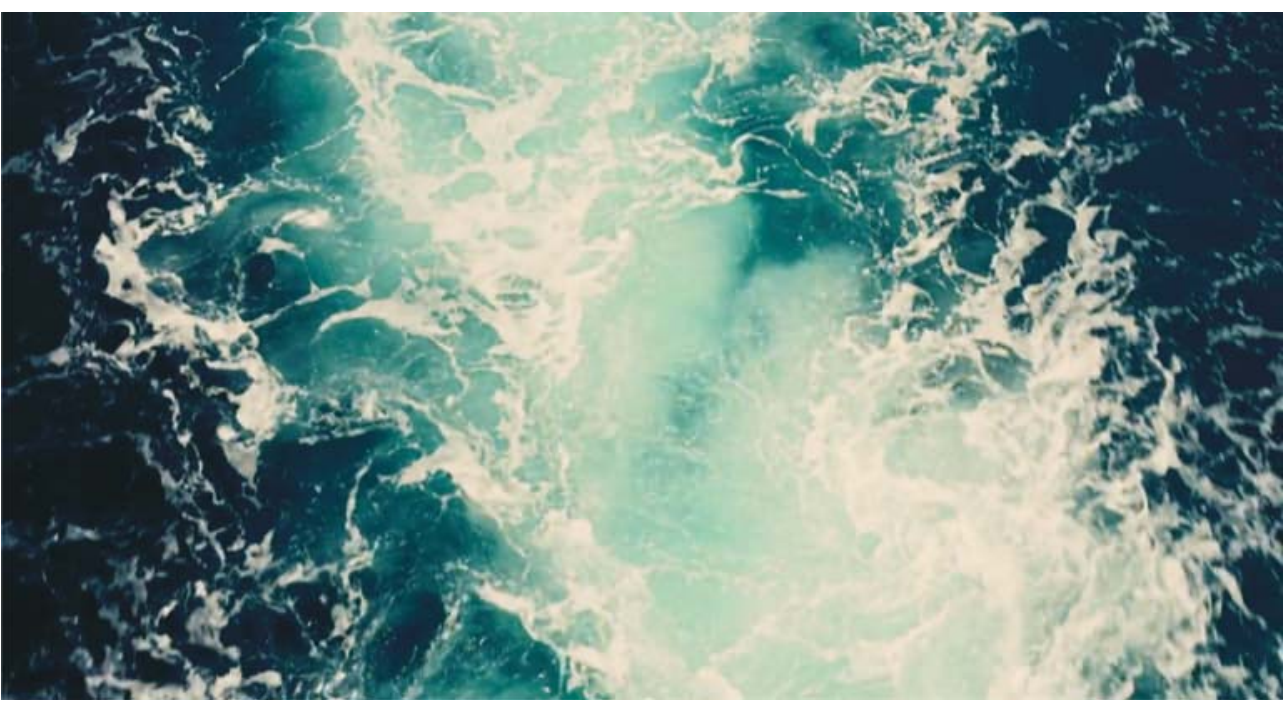

Figure 2. Steadicam progress in the department store.

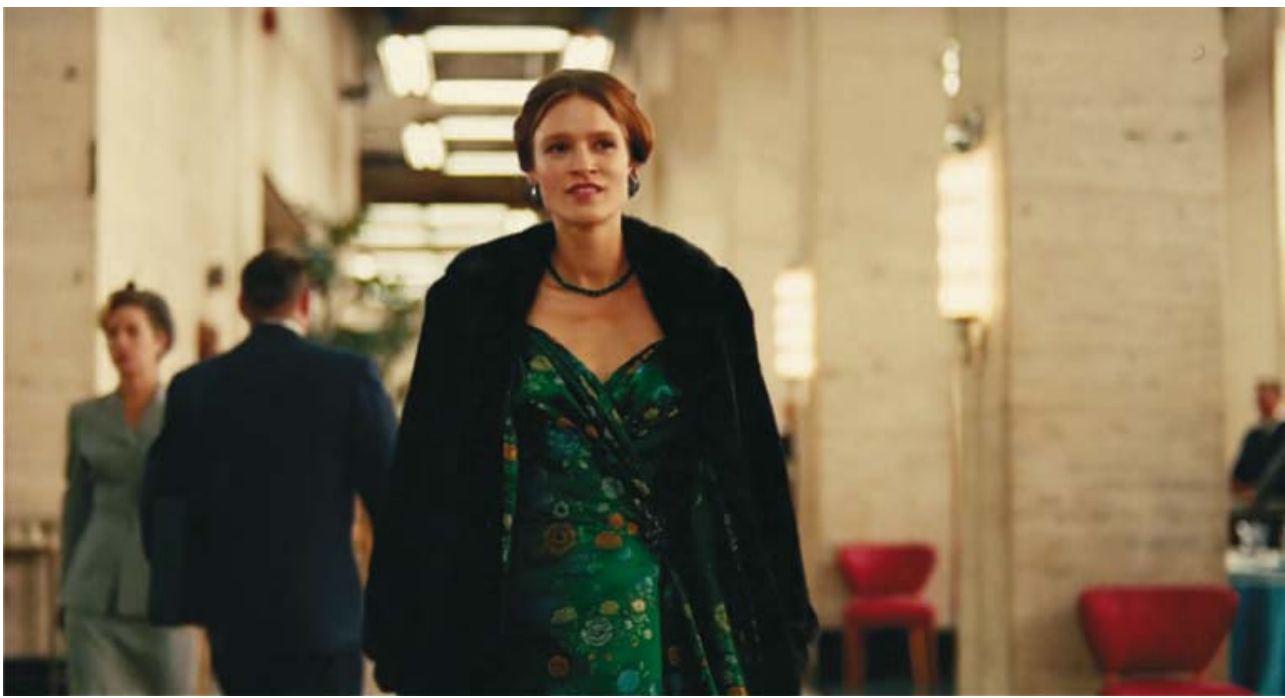


Figure 3. The two protagonists leave the desert.

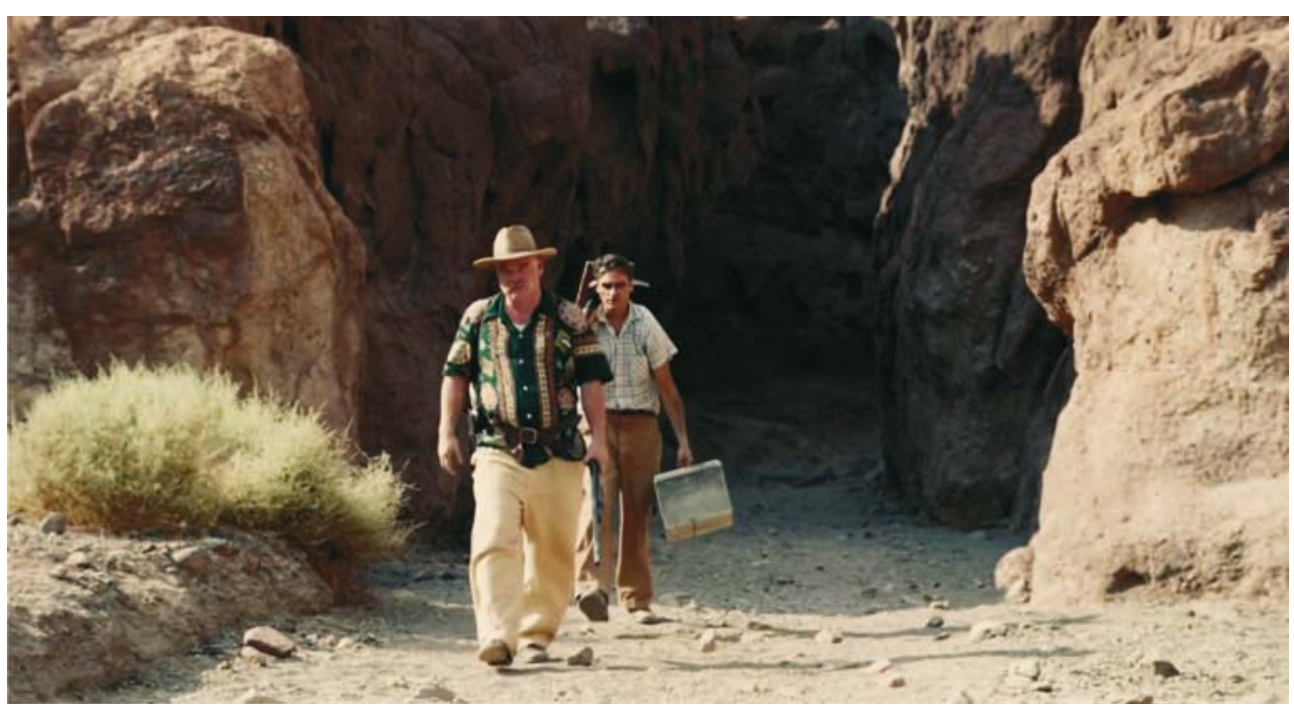

Figure 4. The Master - the first eyeline match cut of the movie.

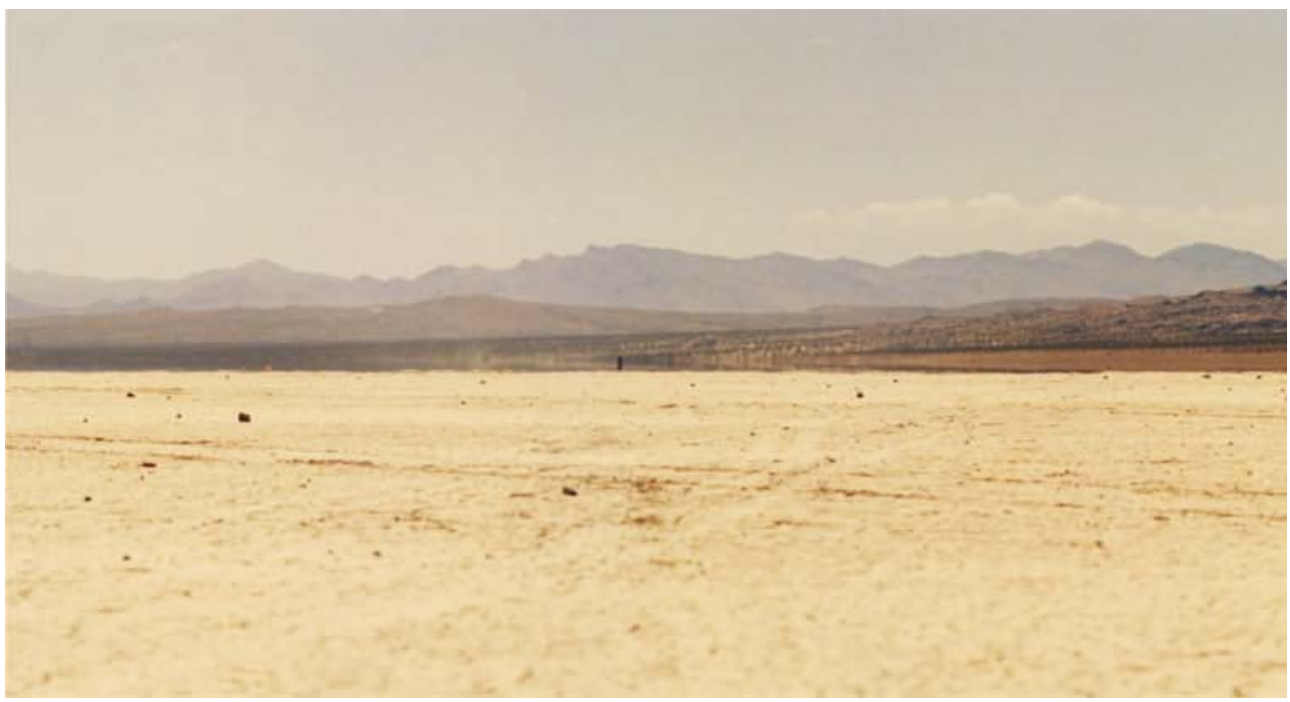

